\title{
The Influence of IT and Learning on Organizational Performance in Small Industries
}

\author{
Mahadi Hasan Miraz ${ }^{1}$, Mohammad Ismail Majumder², Dr. Md. Mamun Habib \\ ${ }^{1}$ School of Quantitative Sciences (SQS), Universiti Utara Malaysia, Malaysia \\ ${ }^{2}$ Master of International Finance, University International Business and Economics (UIBE), China \\ ${ }^{3}$ BRAC School of Business (BBS), BRAC University, Bangladesh \\ Email: ${ }^{1}$ mahadimiraz1@gmail.com, ${ }^{2}$ majumder84@yahoo.com, ${ }^{3}$ mamunhabib@bracu.ac.bd
}

\begin{abstract}
Information Technology (IT) is seen as an important tool in knowledge management processes. However, the existence of IT neither assurances knowledge creation, knowledge supply nor knowledge usage. In addition to IT, a job environment and a culture that inspire sharing and incessant learning should also be created and maintained by management. This paper delivers empirical evidence of the relationship between IT and learning in small businesses as well as their impact on organizational performance. Additionally, the level of sector knowledge-intensity is taken into consideration. Outcomes shows that specific learning along with separate and collaborative information technologies have a positive and significant effect on organizational learning. On the other hand, unlike individual and collaborative information technologies, specific and organizational learning have exposed important and positive effects on organizational performance. Therefore, IT has an important impact on outcomes only when in a proper context of learning is in place. Small businesses in sectors with high knowledge intensity levels are more likely to use of IT.
\end{abstract}

Keywords. IT, learning, sector knowledge-intensity, organizational performance, small businesses.

\section{Introduction}

IT \& learning has become a significant component in business administration. Both kinds of knowledge help management to adapt and anticipate environmental changes through the development of new products or services. IT allows companies to obtain, process, store and exchange information. Furthermore, in a knowledge management context, IT can maintain the conversion within and between implied and explicit knowledge. However, the presence of IT neither guarantees knowledge creation, knowledge distribution nor knowledge use. Some research has stated that many knowledge management systems have been unsuccessful and reported that failure rates of over $80 \%$. However IT profits are clear in well-structured work environments (Schultze \& Boland, 2000; Storey and Barnett, 2000). If the association of effort, with people, farm duties and tools, can be predefined, automation via IT might be the finest selection. In addition, very beginning, the traditional approach for applying IT was through the computerization of existing processes within the borders of traditional designed structures, based on the statement that the original procedure designs were acceptable (Fielder, Grover, and Teng (1994). Troubles arise when this fit cannot be made. That has been the case when applying knowledge management setups. The best of IT cannot be accomplished without processes, rules and habits where sharing and collaboration play important roles.

\section{$2 \quad$ IT and Knowledge Management}

In this paper we emphasis on IT which is dissimilar from info structure. Particularly, IT is a general term for the junction of computers, hardware, software, broadcastings, Internet, electronics and the subsequent technologies. It can be measured through the inventory of applications that organizations exists. While, info system is a wider concept, which mentions to how information flows are considered within organizations so as to meet organizations information requirements (Gunasekaran, Love, Rahimi, \& Miele, 2001). 
Considering the difference between IT and information system, IT can be considered as the structure to knowledge management (Chou, 2003), or an information stage (Tiwana, 2002). Some authors, as Choi and Lee (2003) and Gold et al. (2001), with an alike orientation see IT as an enabler of knowledge management. The role of IT is to spread human capacity of knowledge formation through the speed, memory extension and communication facilities of technology (Baroni \& Arau' jo, 2001).

\section{$3 \quad$ Learning in Organizations}

In this study, learning in organizations is well-defined as the process that increases the actionable knowledge of the organization and its members through interpretation, comprehension and assimilation of tacit and clear information. The purpose is to produce knowledge that can be organized and established in standards of behavior or organizational practices and work procedures.

The purpose of a four-level learning model and this model is not clearly considered for the organization learning (White (1999, Martı'nez-Leo' 2002). In another research Kim differentiates between individual learning and organizational learning but he does not clearly include group learning. Since our research used a sample with a high percentage of companies with less than 15 employees (78.3\%), the two-level model proposed by is the most appropriate for this study (Kim, 1993; Kim, 1993). Due to the firm size, in many cases it is quite difficult to build barriers between groups and the organization since there could be no clear definition of groups rather people performing different tasks according to market and work requirements. Therefore, group learning is considered as a component of Organizational learning.

\section{$4 \quad$ Research Model and Hypotheses}

Fig. 1 shows the suggested model and hypotheses for this study. As it can be seen from Fig. 1, sector knowledge-intensity and organizational performance are presented along with separate technology, collaborative technology, individual learning and organizational learning.

Regarding area of knowledge-intensity, there is no standard classification for it. R\&D share data as well as other non R\&D innovation expenses such as training, market study related to new product expansion, design, patents, licenses, and capital investment have been used as indicators of sector knowledge-intensity (Smith, 2002). Some scholars are focused on analyzing if part knowledge-intensity has an influence on numerous management aspects (Desnoyers \& Lirette, 1999; Smith, 2002). From our point of view, learning and IT use are related to sector knowledge-intensity. The knowledge management structures are not only suitable for consulting and proficient service firms (Alavi and Leidner, 1999). A broad range of organizations from a diversity of industries can profit from these systems. However, it can be predictable that sector knowledge-intensity may influence the ultimate results. Recent statistics from the European Communities (2003) compute that service in high-tech and medium-high-tech manufacturing sectors accounts for $7.4 \%$ of the employment in 2002 in the European Union. Additionally, the percentage for the knowledge-intensive services reaches the $33.3 \%$ of the employment. Consequently, almost half of the employment is related with high and medium tech and knowledge intensive sectors in Europe. Small industries in trades with high knowledge-intensity level might have a bigger use of IT tools as well as managerial performs that encourage learning due to the higher level of pressure to be more innovative. Hence, the following proposition and hypotheses can be drawn (Fig. 1):

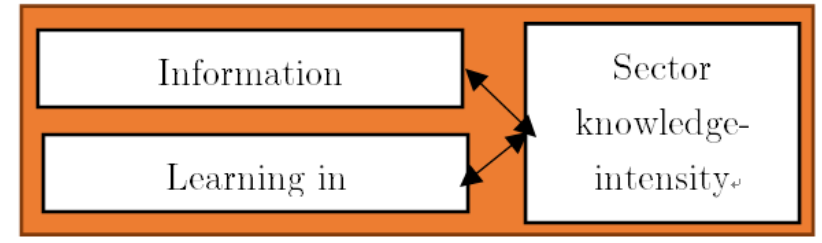

HI-1 


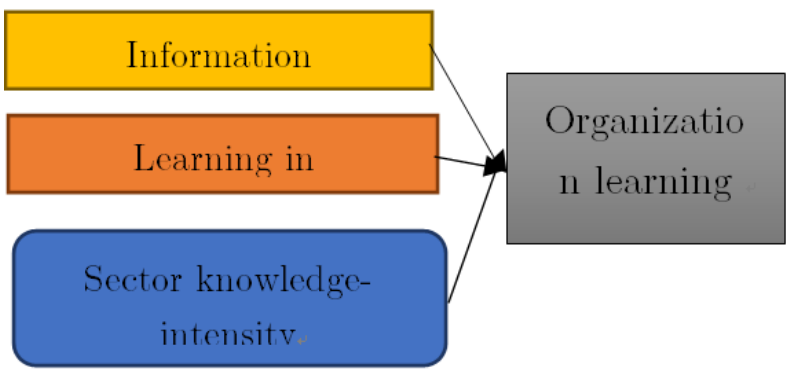

HI-2

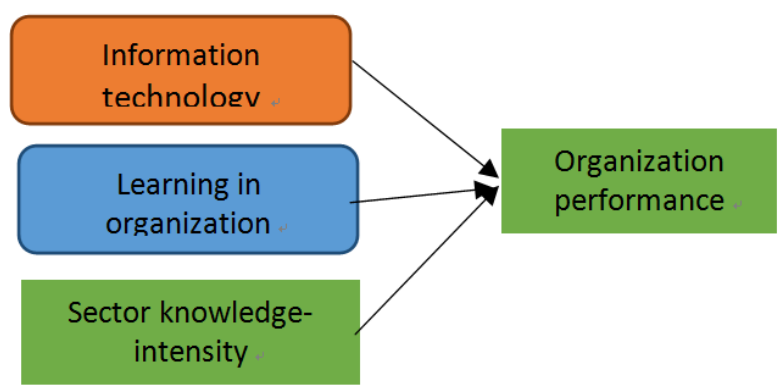

HI-3

Figure 1. IT model and hypotheses

Proposition 1. IT and learning in small industries are related to sector knowledge-intensity.

HI-1. Small businesses within more knowledge-intensity sectors have a higher use of IT.

HI-2. Small businesses within more knowledge-intensity sectors have a bigger use of practices that encourage learning.

Proposition 2. IT, separate learning, and sector knowledge-intensity are related to organizational learning in small businesses.

HI-1. IT has a helpful effect on organizational learning in small businesses.

HII-2. Individual learning has a helpful effect on organizational learning in small businesses.

HII-3. Sector knowledge-intensity has a helpful outcome on organizational learning in small businesses.

Proposition 3. IT, learning, and sector knowledge-intensity are related to organizational performance in small businesses.

HIII-1. IT has an obliging effect on organizational performance in small businesses.

HIII-2. Learning has an obliging effect on organizational performance in small businesses.

HIII-3. Sector knowledge-intensity has an optimistic effect on organizational performance in small businesses.

\section{$5 \quad$ Methodology}

\subsection{Sample and Data Collection}

The target population contains small businesses in the IT sector in the Region of Penang (Malaysia), a total of 123 companies. One hundred and fifty one valid responses have been obtained, yielding an overall response rate of $62.7 \%$. The study assumes an error of $4.9 \%$ for $\mathrm{p}^{1 / 4} \mathrm{q} 1 / 450$ and a confidence level of $94.9 \%$. A structured questionnaire consisting of close-ended questions has been developed.

\subsection{Measures of Variables}

IT: Isolated technology and combined technology are measured through two subscales. Some items are presented in the survey for each of them, one-to-one. Using a dichotomous scale, CEOs have to assess the attendance of each item in their firms. The "distinct technology index" and the "combined 
technology index" are framed as the sum of the values given to the items, in each category. The inner dependability test is weaker for individual technology (0.568) than for combined technology (0.722). The value for the individual technology index, 0.568 , is below 0.60 which is the level considered by as acceptable, but since it is extremely close it is still used (Nunnally, 1978).

Learning: Two sub-scales are established, one for separate learning and one for organizational learning. The Individual learning index is obtained summing the values given by CEOs to 17 items. These items are created to capture the theoretic facets of employee's poly valence and creativity, bravery and determination when facing problems. They also openness values, no resistance to change, goals definition level, autonomy level, failure acceptance and reward system. A seven-point Likert scale is used (for all the items, " 1 " is connected with the last individual learning level, while " 7 " refers to the highest level). The alpha test over the individual learning index (0.677) designates scale dependability. The same procedure is followed to compute the organizational learning index, using 18 items on project-based and teamwork structures, communication skills and systems, experimentation and training.

Sector knowledge-intensity movement: Using the K-means cluster analysis, two significantly different groups of corporations are found according to the "percentage of sale of each product over the overall sales". One group, 57 companies, is perfectly identified as Software businesses. Their key products are "development of customized software and its modifications", "consulting", "telecommunication advanced services", and "training". The other group, comprised of 57 companies, is identified as Hardware businesses whose sales are mainly focused on "hardware and its maintenance". Information from these two sub-sectors, Software and Hardware, is used in order to analyses the result of the "sector knowledge-intensity" variable (Krajewski and Ritzman, 2000). On the other hand, Hardware corporations fit into the "intermediate flow" category defined by the same authors (several products and services produced in comparatively high volumes; equipment's and employees tending to be prepared following the process, and material and/or info assembled according to the existing routes).

\section{$6 \quad$ Results}

The consequences obtained after testing our hypotheses are summarized in Fig. 2. The full set of results can be procurement from the corresponding author.

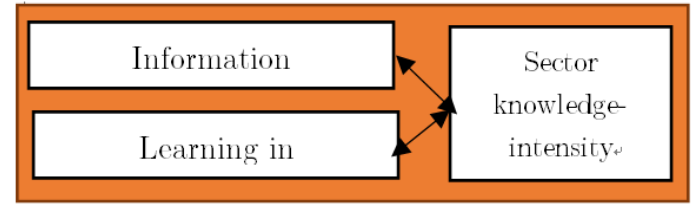

Support to hypotheses. ${ }^{*} \mathrm{p}<0.1 ;{ }^{*} \mathrm{p}<0.05 ;{ }^{* *} \mathrm{p}<0.01$.

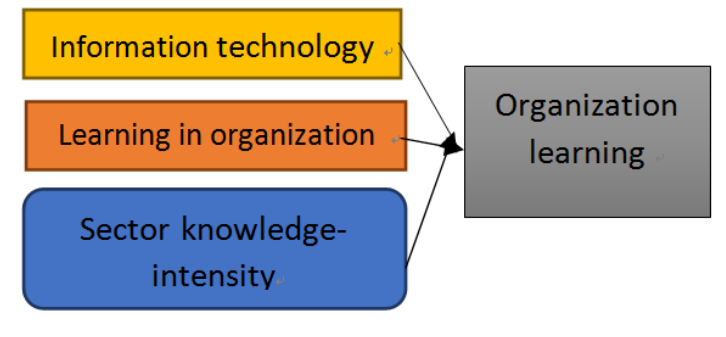

Support to hypotheses. ${ }^{*} \mathrm{p}<0.1 ;{ }^{* *} \mathrm{p}<0.05 ;{ }^{* * *} \mathrm{p}<0.01$. 


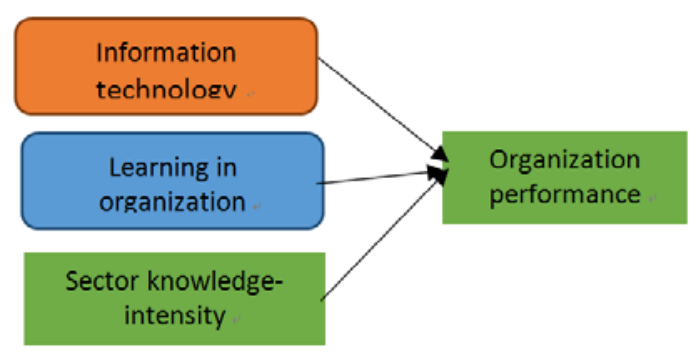

Support to hypotheses. ${ }^{*} \mathrm{p}<0.1 ;{ }^{* *} \mathrm{p}<0.05 ;{ }^{* * *} \mathrm{p}<0.01$.

Figure 2. Hypotheses presentation

With reference to Proposition 1, Hypotheses HI-1 and HI-2 postulate that the mean values of responses for the Software group should be higher than those for the Hardware group on each of the four dimensions (individual technology, collaborative technology, individual learning, and organizational learning). On each test, the p-values are equal or inferior to 0.05, with exception for individual learning. This indicates that the mean response values for Software are significantly higher than the mean response values for Hardware on individual technology, collaborative technology and organizational learning.

\section{$7 \quad$ Conclusions}

Obtaining sustainable competitive benefits depends on structural learning capabilities, which are vital in IT operation in non-structured frameworks. These kinds of settings are classically those of knowledge organization where tacit transmission plays a different role. The aim of this paper is to offer experiential evidence of the connection between IT and learning in small industries as well as their effect on organizational performance.

\section{References}

1. Schultze, U., \& Boland, R. (2000). Knowledge management technology and the reproduction of work practices. Journal of Strategic Information Systems, 9, 193-212.

2. Storey, J., \& Barnett, E. (2000). Knowledge management initiatives: Learning from failure. Journal of Knowledge Management, 4(2), 145-156

3. Fielder, K. D., Grover, V., \& Teng, J. T. C. (1994). Information technology-enabled change: The risks and rewards of business process redesign and automation. Journal of Information Technology, 9, 267-275.

4. Gunasekaran, A., Love, P., Rahimi, F., \& Miele, R. (2001). A model for investment justification in information technology projects. International Journal of Information Management, 21, 349-364.

5. Tiwana, A. (2002). The knowledge management toolkit: Orchestrating IT, strategy, and knowledge platforms. Englewood Cliffs, NJ: Prentice-Hall.

6. Chou, S. (2003). Computer systems to facilitating organizational learning: IT and organizational context. Expert Systems with Applications, 24, 273-280.

7. Gold, A., Malhotra, A., \& Segars, A. (2001). Knowledge management: An organizational capabilities perspective. Journal of ManagementmInformation Systems, 18(1), 185-214.

8. Baroni, R., \& Arau' jo, M. (2001). Using information technology to support knowledge conversion processes. Information Research, 7(1).

9. Martı'nez-Leo' n, I. (2002). El aprendizaje en las organizaciones. aplicacio'n al sector agroalimentario. Ph.D. dissertation, Polytechnic University of Cartagena, Spain.

10.Kim, D. H. (1993). The link between individual and organizational learning. Sloan Management Review, 35(1), $37-50$.

11.Desnoyers, A., \& Lirette, Y. (1999). The knowledge-based economy and the labour market. Human Resources Development Canada.. 
12.Alavi, M., \& Leidner, D. (1999). Knowledge management systems: Issues, challenges and benefits. Communications of the Association for Information Systems, 1 (Issue 2es), article 1.

13.European Communities (2003). High-tech and knowledge-intensive sectors creating employment in Europe. Eurostat: Science and technology, theme 9-10/2003.

14.Nunnally, J. (1978). Psychometric theory. New York: McGraw-Hill.

15.Krajewski, L. J., \& Ritzman, L. P. (2000). Administracio’n de operaciones: Estrategia y ana'lisis. Pearson Educacio’n: Me’xico. 